\title{
1 Applying genomic data to seagrass conservation
}

2 Nikki L Phair, Erica S Nielsen, Sophie von der Heyden

Evolutionary Genomics Group, Department of Botany and Zoology, University of 4 Stellenbosch, Private Bag X1, Matieland, 7602, South Africa

5

\section{Abstract}

7

8

9

11

Although genomic diversity is increasingly recognised as a key component of biodiversity, it is seldom used to inform conservation planning. Estuaries and keystone species such as the southern African seagrass, Zostera capensis, are under severe anthropogenic pressure and are often poorly protected. In this study we integrated SNP data generated from populations of Z capensis across the South African coastline into the spatial prioritisation tool Marxan. We included different measures of genomic variation to account for genomic diversity, distinctness and evolutionary potential to explore spatial planning scenarios. We investigated how conservation priority areas identified by targeting only habitat type, differed from those identified by also including genomic measures; further we assessed how different genetic diversity metrics change prioritisation outcomes. All scenarios targeting genomic variation identified unique conservation prioritisation areas compared to scenarios only targeting habitat type. As such, omitting these estuaries from regional MPA networks risks the loss of evolutionarily important populations, threatening resilience and persistence of associated estuarine communities and their ecosystem services. We also observed a high degree of overlap between prioritisation outcomes across targeted measures of genomic variation. As such, by including even single measures of genomic variation, it 
may be possible to sufficiently represent the evolutionary processes behind the patterns of variation, while simplifying the conservation prioritisation procedure.

\section{Introduction}

Estuaries are some of the most dynamic coastal systems globally and are important for supporting high levels of biodiversity and foundational species such as saltmarshes, elevated levels of carbon sequestration, supporting regional fisheries and maintaining water quality (Bertelli and Unsworth 2014; Jackson et al. 2015). However, most coastal ecosystems, including estuaries, are under intense anthropogenic pressures due to their proximity to human populations (Mead et al. 2013; Little et al. 2017). Further, these systems are expected to be at increased risk of habitat degradation in future decades due to climate change, which will only be further exacerbated by human induced pressures. South Africa is no exception, even accounting for the progress made in establishing 20 new MPAs, for a total of 42 (Skowno et al. 2019). Yet, many of South Africa's existing coastal MPAs are ineffective, with fishing effort in estuaries up to five times higher inside compared to outside restricted areas (Skowno et al. 2019). This leaves foundational species, such as the seagrass Zostera capensis, and their vital ecosystems services vulnerable.

Increased pressures on coastal systems are especially concerning as models project around $30 \%$ of seagrass-suitable habitat will be lost along the South African coastline by the year 2070 (Phair 2016). In reality, Z. capensis declines may be even more extreme as the effects of climate change are compounded by human pressures (Adams 2016). 
Indeed, declines and local extirpations of Z. capensis have already been recorded

(Human et al. 2016) and given its disjunct distribution, once Z. capensis is lost in a

particular estuary, it is unlikely to be recolonised from elsewhere (Adams 2016). In

addition, Z. capensis is highly clonal, with distinct evolutionary dynamics that separate

two historically divergent clusters (Phair et al. 2019), where lowered genomic diversity

is associated with anthropogenic pressures (Phair et al. 2020). The combination of these factors question the persistence of Z. capensis in South Africa and are likely to increase the loss of meadows further. In order to safeguard the future of Z. capensis and its associated biodiversity and human benefits, increasing the number and quality of marine and coastal protected habitat is crucial.

The extent to which protected areas succeed in protecting biodiversity relies primarily

on meeting two key objectives, representativeness and persistence (Margules \& Pressey 2000). Protected areas should capture a representative sample of the full range of biodiversity across levels of organisation including genetic diversity, which is increasingly recognised as a key component of biological diversity. In fact, evidence is mounting that including genetic data into conservation planning is essential to incorporate evolutionary potential and enhance contemporary and future management of natural resources (Beger et al. 2014; Carvalho et al. 2017; Nielsen et al. 2017; DinizFilho et al. 2018; Paz-Vinas et al. 2018). Evolutionary potential is an important facet in conservation planning, as it underpins the capacity of species and populations to adapt 
Genomic techniques, specifically those based around Single Nucleotide Polymorphism

72

73

74

75

76

77

78

79

80

81

82

83

84

85

86

88

89

90

91

92

93

(SNP) identification have led to significant advances in marine conservation as they can

better account for resilience and persistence (compared to for example mitochondrial

DNA or microsatellites, that predominantly provide insights into neutral evolutionary

processes), and improve our understanding of the mechanisms behind adaptation and

speciation (Nielsen et al. 2009; Allendorf et al. 2010; Reitzel et al. 2013; McMahon et al.

2014; Gaither et al. 2018; Nielsen et al. 2018), as well as connectivity (Nielsen et al.

2017; Rodriguez-Ezpeleta et al. 2017). Both standing genomic diversity and local

adaptation can increase evolutionary resilience, and should therefore be considered

when planning MPAs with the aim of enhancing species persistence through climate

change (Sgrò et al. 2011; Bible \& Sanford 2016). For this purpose, it may be useful to

apply a genomic approach to the conservation of a keystone estuarine species such as $Z$.

capensis, which also functions as an umbrella species whose conservation ensures the

protection of many other species.

In this study, we utilised an existing SNP data set to explore conservation outcomes for the endangered seagrass, Zostera capensis throughout its distribution in South Africa.

Specifically, we integrated different measures of genomic variation to account for

genomic diversity, distinctness and evolutionary potential using the spatial

prioritisation tool Marxan, to assess conservation prioritisation under different genomic scenarios. We looked at 1 ) how conservation priority areas identified by targeting only habitat differed from those identified by also targeting different genomic measures, and 2) how different genomic metrics change prioritisation outcomes. This study

contributes towards building a framework to better understand the impact of different types of genomic data on spatial planning for vulnerable coastal ecosystems. 


\section{Methods}

\section{Data utilised in analyses}

Genomic data for this study was generated through a pooled restriction site-associated sequencing (RADseq) approach by Phair et al. (2019) (NCBI PRJNA503110; GeOMe project: Zostera capensis pooled RADseq; GitHub:

100 https://github.com/vonderHeydenLab/Zostera-capensis-genomics). In short, $Z$. capensis samples from eight locations (Olifants, Berg, Breede, Knysna, Swartkops, Nahoon, Mngazana and Richard's Bay Estuary) across the South African distribution of this species was used to generate a pooled sequencing library. A total of 30 leaf samples per location were collected, with sampling spread throughout meadows to minimise accidental sampling of clonal plants (permit number 0028-AAA008-00159; see Rellstab et al. (2017), Christe et al. (2017) and Jahnke et al. (2019) for sampling clonal and partially clonal plants for pool-seq). Post DNA extraction, DNA was equimolarly pooled by location for ezRAD library preparation and sequencing (Toonen et al. 2013; Knapp et al. 2016; Nielsen et al. 2018); sequence alignment and bioinformatics are described in

111 Genomic measures included in spatial prioritisation scenarios

In order to identify conservation priority areas under various scenarios, the following measures of genomic diversity were included in the analysis: nucleotide diversity $(\mathrm{N})$, expected heterozygosity $(\mathrm{H})$, allelic richness (AR), the number of shared SNPs $(\mathrm{S})$ and private SNPs (PS) as a proportion of the number of total SNPs per population. We also included a measure of evolutionary potential in the form of statistical outliers, that may signal site-specific selection. Combined, the metrics cover distinctness and diversity 
(Hoban et al. 2020), with each able to address unique conservation objectives (Table 1).

The decision support tool, Marxan v 2.43 (Ball et al. 2009), was used to design networks of MPAs as possible scenarios for the preservation of Z. capensis. Marxan uses an algorithm which minimises reserve cost and size whilst meeting a set of predefined biodiversity targets. South African estuaries were used as planning units. Reserve cost was derived from the fishing effort per estuary quantified in the National Biodiversity Assessment (NBA: van Niekerk et al. 2012) and represents the cost as lost opportunity for industry if MPAs are established as no-take reserves. Habitat data classifying estuaries as permanently open, temporarily open/closed, an estuarine bay or an estuarine lake was obtained from Adams (2016). A baseline scenario was established by targeting $20 \%$ of each estuarine habitat type as suggested by the NBA (Skowno et al. 2019), whilst applying the cost layer. Each genomic scenario was developed using the baseline scenario as a foundation (Table 2). The procedures outlined in "Marxan good

Conservation decision tools such as Marxan require genomic point data to be interpolated throughout the entire planning region to form a spatially continuous surface layer. Accordingly and following Beger et al. (2014) and Nielsen et al. (2017), an Inverse Distance Weighting procedure in ArcMap v10.1 (ESRI, Redlands CA) was used to interpolate genomic data across South African estuaries. The reclassification (reclass) tool in ArcMap v10.1 (ESRI, Redlands CA) was used to reclassify the data from each 
genomic metric into high, medium and low classes using natural breaks in the data. As both high and low values of genomic diversity are significant in terms of evolutionary processes, targets were set to represent $50 \%$ of high and low classes, and $30 \%$ of the medium class of each genomic metric following a similar protocol to Beger et al. (2014) and Nielsen et al. (2017).

In addition to the baseline scenario, additional scenarios were run to cover different aspects genomic variability, thus allowing for the comparison of the use of different genomic measures in identifying conservation priority areas (Table 2). Combinations of genomic measures were included in order to observe how priority areas identified change with the addition of data. As it is possible for many different configurations of planning units to meet the conservation objectives, each scenario run was repeated 100 times to account for any system variability, allowing Marxan to calculate planning unit selection frequencies and identify the best solution as the one with the lowest cost to target ratio.

QGIS v2.18.4 (“QGIS Development Team. 'QGIS Geographic Information System. Open Source Geospatial Foundation Project.'” 2012) was used to visualise scenario outcomes by means of the QMarxan plugin v 1.3 .1 (Game \& Grantham 2008). Planning unit selection frequencies were obtained from the 'ssol' (summed solution) outputs and plotted along the South African coastline for each scenario. In order to understand whether different measures of genomic diversity prioritise different regions, unique and shared priority planning units among diversity scenarios $(\mathrm{N}, \mathrm{H}, \mathrm{AR}, \mathrm{S})$ were identified from the 'best' solution outputs and plotted.

We then selected one of these measures of diversity, AR, to represent diversity in subsequent analyses alongside a measure of distinctness (PS), putative adaptive 
variation (AV) and a combination of all (ALL). We chose allelic richness as it is often

considered the most useful measure for monitoring even short-term changes in populations, because of its sensitivity to population declines (Schwartz et al. 2007; Hoban et al. 2014; Gedeon et al. 2017; Phair et al. 2020). For this subset of scenarios (AR, PS, AV, ALL), the differences from and similarities to the baseline scenario, in terms of planning units selected, was obtained from 'best' solution outputs and plotted to visualise the impact of including measures of genomic diversity, distinctness and potential adaptive variation in conservation planning in addition to habitat data.

175

Planning unit selection frequencies from the ALL scenario were also plotted alongside estuary threat status, as defined by the NBA (van Niekerk et al. 2018), to visualise the overlap between evolutionary potential and estuarine pressures.

In order to view dissimilarities among scenario solutions, we followed the approach in Harris et al. (2014) and applied nonmetric multidimensional scaling (nMDS) ordination based on Jaccard resemblance matrices in the statistical environment R ( R Core Development Team 2008) using Rstudio V 0.98.1102 (“RStudio” 2012). Pearson's correlation tests were carried out on the selection frequency values for each planning unit to quantify spatial similarities between each pair of scenarios.

\section{Results}

\section{Spatial conservation prioritisation}

All scenarios prioritised estuaries for conservation across the coastline, however the

baseline scenario selected estuaries at a lower frequencies than scenarios targeting any of the genomic measures (Fig. 1). Although Pearson correlation tests revealed significant $(\mathrm{p}<0.05)$ correlations between all scenarios, there were differences in the spatial distribution of prioritised estuaries and the frequency with which they were 
selected between scenarios targeting genomic measures (Fig. 1). More specifically, $\mathrm{H}$ and PS selected fewer estuaries along the west coast, scenarios $\mathrm{N}$ and S fewer along the south coast, and scenarios AR, AV and ALL fewer along the east coast, than other scenarios. Only scenario H and ALL selected the prominent St. Lucia estuary on the east coast. Scenarios N, S and SP selected estuaries at a slightly higher frequency than other scenarios (Fig. 1). Hotspots for the conservation of genomic diversity, distinctness and potential adaptive variation exist along the west, south-west and east coasts, as planning units in these regions were selected at high frequencies across genomic scenarios (Fig. 1).

\section{Scenario dissimilarities}

When scenario dissimilarities were visualised by means of an nMDS plot, the baseline scenario formed a discrete cluster, distant to all other scenarios, with the exception of one anomalous solution (Fig. S1). Solutions from each genomic scenario formed distinct clusters, with solutions from AR and $\mathrm{H}$ scenarios most removed from the other genomic scenario clusters, and the ALL scenario displaying the broadest range of solutions.

Further, solutions from N, S and PS group closely together, and those from AV fall almost within the ALL cluster of solutions. For many scenarios, such as B and AR, only a few solutions are visible due to highly overlapping nature of these solutions, where Marxan identified the same configuration of priority estuaries in multiple runs.

209 Genomic diversity scenarios

Although most prioritised estuaries overlapped across genomic diversity scenarios (AR,

$\mathrm{H}, \mathrm{N}$ and S), each diversity scenario also highlighted unique estuaries for conservation compared to the other diversity scenarios (Fig. 2). Scenario S identified the highest 
coast (Fig. 2). Scenario H only identified one unique estuary for conservation, St. Lucia

(Fig. 2). Scenario AR selected unique estuaries for conservation along the south coast and scenario $\mathrm{N}$ along the south and east coasts (Fig. 2).

\section{Genomic diversity vs distinctness vs potential adaptive variation}

The majority of prioritised estuaries were identified across the baseline (habitat)

scenario and scenarios targeting diversity (AR), distinctness (PS), potential adaptive variation (AV) and ALL. However, each of these scenarios also identified unique estuaries that were gained or lost compared to the baseline (Figure 4). Scenario PS was the most dissimilar from the baseline scenario, as it showed the greatest number of estuaries gained and lost with respect to those selected by the baseline scenario, which is also evident from the nMDS plot (Fig. S1).

When comparing the planning unit selection frequency of the ALL scenario with the

threat status of estuarine systems, the majority of the critically endangered and vulnerable estuaries are captured (Fig. 4). However, there is little overlap with the current coastal MPA network (Skowno et al. 2019), particularly along the west and south coasts, where many estuaries are classified as critically endangered or endangered, and are highlighted by their evolutionary importance (Fig. 4).

\section{Discussion}

With the threats to coastal systems escalating due to climate change and increasing anthropogenic pressures, MPA networks are vital for the persistence of coastal species and associated ecosystem services. Seagrasses provide a broad array of services that support both biodiversity and human well-being and are thus crucial for coastal 
ecosystem health, with Z. capensis identified as an important keystone species in South African estuarine systems (Adams 2016). Although it is recognised that genomic diversity is important for species and ecosystem resilience (Benestan et al. 2016; Evans et al. 2017a, b; Timpane-Padgham et al. 2017), there are limited examples of evolutionary patterns, particularly potential adaptive variation (Pearse 2016), integrated into actionable conservation and management plans (Sork et al. 2009; Laikre et al. 2009; Laikre 2010; Beger et al. 2014; von der Heyden et al. 2014; Nielsen et al. 2017; von der Heyden 2017; Hoban et al. 2020). One reason for this is because there is no clear evidence for how different genetic and genomic measures vary within a conservation planning framework, hindering their uptake into a more formalised process identifying priority areas. This study provides unique spatial plans that not only compare different metrics that capture genomic diversity, distinctness, and potential signals of local adaptation, but also provide some insights into the feasibility of including these measures into a conservation plan for Z. capensis in South Africa. Notably, this study illustrates the importance of including genomic information in MPA planning, and the risk to the evolutionary processes which drive genomic patterns if management plans are based solely on habitat level data.

\section{Importance of genomic data in spatial planning}

Although priority areas overlapped across all scenarios, as they were all founded on

baseline habitat data, baseline and genomic scenarios identified noticeably different estuaries for conservation (Fig. 1). This is consistent with findings from other single species (Beger et al. 2014) and even multi-species approaches (Nielsen et al. 2017), and highlights potentially significant omissions in traditional habitat-based MPA design. As genomic diversity is foundational for adaptation and resilience to environmental 
change, excluding such data from planning seriously undermines future persistence of natural populations (von der Heyden 2009; Beger et al. 2014; von der Heyden et al. 2014). Within the context of our study, this has important implications for futureproofing Z. capensis populations along the South African coast, where many estuaries are under intense anthropogenic pressures (van Niekerk et al. 2018; Skowno et al. 2019; Fig. 4). It is essential that genomic data is included as it offers unique insights into the species resilience. Further, failing to conserve current genomic variation of $Z$. capensis increases the probability of losing genotypes which may be more resilient to environmental change. This has already been demonstrated in Phair et al. (2020) where anthropogenic stressors were observed to play an important role in reducing genomic diversity, likely because of the loss of resilient genotypes. This is highly problematic, as numerous seagrass studies suggest that genomic diversity is linked to increased resistance and resilience in various forms (Massa et al. 2013; Jahnke et al. 2015; Phair et al. 2020; Table 1). Although single species approaches in conservation management are often criticised as any one species may not be representative of the broader ecosystem (Richardson et al. 2016; Anthonysamy et al. 2018), their use is recognisably justified when dealing with keystone species such as seagrasses, where conserving such 'umbrella' species can ensure the protection of a wide range associated biodiversity (Simberloff 1998; Hughes et al. 2009).

Measures of genomic diversity, distinctness and adaptation resolve different

conservation priorities

Genomic diversity scenarios (AR, H, N, S) all identified statistically similar areas for conservation prioritisation. Between one and 15 priority planning units unique to each scenario were identified, whilst all others were shared among scenarios (Fig. 2). This 
suggests that conserving a proportion of estuaries with low, medium and high variation for any single genomic diversity measure may sufficiently capture priority estuaries identified by other measures. This has also been observed for measures of genetic diversity (from mtDNA), where Nielsen et al. (2017) consistently identified congruent patterns of spatial prioritisation when targeting haplotype diversity, nucleotide diversity, local genetic differentiation and private alleles, providing support that targeting multiple classes of any one measure of genetic variation can adequately represent the evolutionary patterns observed in other genetic metrics. In this regard, the process of integrating genomic information into spatial planning may be somewhat simplified for conservation managers by employing the most easily obtainable genomic measures.

In addition to measures of diversity it is also important to consider distinctness, where conservation objectives can focus on uniqueness or similarity. For example, highly structured populations may harbour unique genetic variants that could be of conservation concern, whereas less structured populations are likely to have some connectivity and thus be more resilient to perturbations (Chust et al. 2013; Grech et al. 2018). Genomic distinctness scenarios (here measured as private SNPs unique to populations) identified estuaries along the entire coastline. As the scenario targeted various levels of genomic distinctness, these estuaries represent meadows with both high and low levels of connectivity. For example, estuaries on the west coast may be more distinct than those clustered on the south and east coasts, which may be more highly connected (Fig. 3). This approach is beneficial as it safeguards evolutionary potential in a two-pronged approach, firstly, by preserving more homogeneous 
adjacent well-connected populations (McMahon et al. 2017; Grech et al. 2018) and secondly, by preserving locally adapted populations that may be pre-adapted to specific

In order to preserve evolutionary potential, it is important to consider potential adaptive variation in addition to distinctness and diversity, as locally adapted genetic variants may exhibit population-specific responses to the environment (Sgrò et al. 2011; Carvalho et al. 2017; Hoban 2018; Razgour et al. 2018). Notably, the scenario targeting potential adaptive variation (AV) identified priority areas distinct from the baseline habitat scenario, on the west, south and north-east coasts (Fig. 3). These regions could represent areas of high adaptive potential and therefore resilience to environmental change, under the assumption that the statistical outliers detected in Phair et al. (2019) are indeed of adaptive importance and have conservation relevance. As different genomic metrics may highlight different priority areas, it is important to carefully choose metrics based on conservation objectives.

Although RAD-seq generated genomic data provides an abundance of evolutionary information, it is also important to acknowledge its limitations, particularly in the

potential bias introduced when identifying putative outlier loci (Kofler et al. 2016;

Lowry et al. 2017a, b). Even so, the use of genomic data in conservation is increasingly being advocated for (Funk et al. 2012; Hohenlohe et al. 2017; Lowry et al. 2017a), and conservation practitioners should account for such uncertainty in genomic data as they would with other biological data which informs conservation decisions (Kujala et al. 2013). 
Our studies shows mismatch between sufficient protection and the distribution and intensity of anthropogenic pressures on estuaries along the coastline (van Niekerk et al. 2018; Fig. 4). The recent expansion of the MPA network is an important step in protecting biodiversity and increasing sustainability, however more focus could still be given to foundational coastal ecosystems, including estuaries. The mismatch between estuarine protection and threat level is particularly evident on the south and south-west coasts, where there are a high number of estuaries rated as endangered and critically endangered in terms of a loss of function and structure due to anthropogenic and climate pressures (Fig. 4). Further, these estuaries correspond to areas identified as priorities for conservation by genomic scenarios (Fig. 4). As such, omitting these estuaries from MPA networks risks the loss of evolutionarily important populations of Z. capensis and could threaten the resilience and persistence of not only this keystone species, but also estuarine associated communities. Going forward, MPAs should be reviewed in order to ensure persistence and representativeness of evolutionary potential of keystone species, and thus estuarine associated communities and

$348 \quad$ Literature Cited

Adams JB. 2016. Distribution and status of Zostera capensis in South African estuaries - A review. South African Journal of Botany 107:63-73.

Allendorf FW, Hohenlohe P a, Luikart G. 2010. Genomics and the future of conservation genetics. Nature reviews. Genetics 11:697-709. Nature Publishing Group. Available from http://dx.doi.org/10.1038/nrg2844. 
Anthonysamy WJB et al. 2018. Population genetic evaluations within a co-distributed taxonomic group: a multi-species approach to conservation planning. Animal Conservation 21:137-147.

Ardron JA, Possingham HP, Klein CJ. 2010. Marxan good practices handbook, version 2. Page (Ardron JA, Possingham HP, Klein CJ, editors). Pacific Marine Analysis and Research Association, Victoria, BC, Canada. Available from www.pacmara.org.

Ball IR, Possingham HP, Watts ME. 2009. Marxan and Relatives: Software for Spatial Conservation Prioritization. Pages 185-195 Spatial conservation prioritization: quantitative methods and computational tools. Oxford University Press, Oxford. Available from http://www.uq.edu.au/spatialecology/docs/Publications/2009_Ball_etal_MarxanA ndRelatives.pdf.

Beger M, Selkoe KA, Treml E, Barber PH, Crandall ED, Toonen RJ, Riginos C. 2014. Evolving coral reef conservation with genetic information. Bulletin of Marine Science 90:1-28.

Benestan L, Ferchaud A-L, Hohenlohe P, Garner BA, Naylor GJP, Baums I, Schwartz M, Kelley JL, Luikart G. 2016. Conservation genomics of natural and managed populations: building a conceptual and practical framework. Molecular ecology. Available from http://www.ncbi.nlm.nih.gov/pubmed/27086132.

Bertelli CM, Unsworth RK. 2014. Protecting the hand that feeds us: Seagrass (Zostera marina) serves as commercial juvenile fish habitat. Marine Pollution Bulletin 83:425-429. Available from https://www.researchgate.net/profile/Richard_Unsworth/publication/25637667 
6_Protecting_the_hand_that_feeds_us_Seagrass_\%28Zostera_marina\%29_serves_as _commercial_juvenile_fish_habitat/links/00b49529dba1a8ede0000000.pdf.

379

380

381

382

383

384

385

386

387

388

389

390

391

Bible JM, Sanford E. 2016. Local adaptation in an estuarine foundation species: Implications for restoration. BIOC 193:95-102. Elsevier B.V. Available from http://dx.doi.org/10.1016/j.biocon.2015.11.015.

Carvalho SB, Velo-Antón G, Tarroso P, Portela AP, Barata M, Carranza S, Moritz C, Possingham HP. 2017. Spatial conservation prioritization of biodiversity spanning the evolutionary continuum. Nature Ecology and Evolution 1:1-8.

Christe C, Stolting KN, Paris M, Fraïsse C, Bierne N, Lexer C. 2017. Adaptive evolution and segregating load contribute to the genomic landscape of divergence in two tree species connected by episodic gene flow. Molecular Ecology 26: 59-76.

Chust G et al. 2013. Connectivity, neutral theories and the assessment of species vulnerability to global change in temperate estuaries. Estuarine, Coastal and Shelf Science 131:52-63. Available from http://dx.doi.org/10.1016/j.ecss.2013.08.005.

Diniz-Filho JAF et al. 2018. Overcoming the worst of both worlds: integrating climate change and habitat loss into spatial conservation planning of genetic diversity in the Brazilian Cerrado. Biodiversity and Conservation. Available from https://link.springer.com/article/10.1007/s10531-018-1667-

y?utm_source=researcher_app\&utm_medium=referral\&utm_campaign=MKEF_USG _Researcher_inbound.

Evans SM, Sinclair EA, Poore AGB, Bain KF, Vergés A. 2017a. Assessing the effect of genetic diversity on the early establishment of the threatened seagrass Posidonia australis using a reciprocal-transplant experiment. Restoration Ecology 26:1-11. 
400

401

402

403

404

405

406

407

408

409

410

411

412

418

420

421

Evans SM, Vergés A, Poore AGB, Gallagher F. 2017b. Genotypic Diversity and Short-term Response to Shading Stress in a Threatened Seagrass : Does Low Diversity Mean Low Resilience ? Frontiers in plant science 8:1-11.

Gaither MR et al. 2018. Genomics of habitat choice and adaptive evolution in a deep-sea fish. Nature Ecology and Evolution 2:1-8.

Game ET, Grantham HS. 2008. Marxan user manual: for Marxan version 1.8.10. University of Queensland, St. Lucia, Queensland, Australia, and Pacific Marine Analysis and Research Association, Vancouver, British Columbia, Canada.

Gedeon CI, Hoffmann IE, Váczi O, Knauer F, Ben Slimen H, Stefanović M, Lehoczky É, Laborczi A, Suchentrunk F. 2017. The role of landscape history in determining allelic richness of European ground squirrels (Spermophilus citellus) in Central Europe. Hystrix 28:240-246.

Grech A, Hanert E, Mckenzie L, Rasheed M, Thomas C, Tol S, Wang M, Waycott M, Wolter J, Coles R. 2018. Predicting the cumulative effect of multiple disturbances on seagrass connectivity. Global Change Biology 24:3093-3104.

Harris LR, Watts ME, Nel R, Schoeman DS, Possingham HP. 2014. Using multivariate statistics to explore trade-offs among spatial planning scenarios. Journal of Applied Ecology 51:1504-1514.

Hoban S. 2018. Integrative conservation genetics: Prioritizing populations using climate predictions, adaptive potential and habitat connectivity. Molecular Ecology Resources 18:14-17. Available from http://doi.wiley.com/10.1111/17550998.12752. 
422

423

424

425

426

427

428

430

431

436

Hoban S et al. 2020. Genetic diversity targets and indicators in the CBD post-2020 Global Biodiversity Framework must be improved. Biological Conservation 248:108654. Elsevier Ltd.

Hoban S, Arntzen JA, Bruford MW, Godoy JA, Rus Hoelzel A, Segelbacher G, Vilà C, Bertorelle G. 2014. Comparative evaluation of potential indicators and temporal sampling protocols for monitoring genetic erosion. Evolutionary Applications 7:984-998.

Hohenlohe PA, Bernatchez L, Funk WC, Catchen JM. 2017. Unbroken : RADseq remains a powerful tool for understanding the genetics of adaptation in natural populations. Molecular resources 17:362-365.

Hughes AR, Williams SL, Duarte CM, Heck KL, Waycott M. 2009. Associations of concern: Declining seagrasses and threatened dependent species. Frontiers in Ecology and the Environment 7:242-246.

Jackson E, Wilding C, Attrill M. 2015. Use of a seagrass residency index to apportion commercial fishery landing values and recreation fisheries expenditure to seagrass habitat service. Conservation Biology 29:899-909. Available from http://onlinelibrary.wiley.com/doi/10.1111/cobi.12436/full (accessed June 23, 2015).

Jahnke M, Gullstrom M, Larsson J, Asplund ME, Mgeleka S, Silas MO, Hoamby A, Mahafina J, Nordlund LM. 2019. Population genetic structure and connectivity of the seagrass Thalassia hemprichii in the Western Indian Ocean is influenced by predominant ocean currents. Ecology and Evolution 9: 8953-8964. Avialable from https://doi.org/10.1002/ece3.5420 (accessed June 23, 2015). 
Jahnke M, Olsen JL, Procaccini G. 2015. A meta-analysis reveals a positive correlation between genetic diversity metrics and environmental status in the long-lived seagrass Posidonia oceanica. Molecular ecology 24:2336-48. Available from http://doi.wiley.com/10.1111/mec.13174 (accessed April 25, 2015).

Knapp I, Puritz J, Bird C, Whitney J, Sudek M. 2016. ezRAD-an accessible next-generation RAD sequencing protocol suitable for non-model organisms v3. 1. Available from https://scholar.google.co.za/scholar?hl=en\&as_sdt=0\%2C5\&q=ezRADan+accessible+next-generation+RAD+sequencing+protocol+suitable+for+nonmodel+organisms\&btnG= (accessed January 11, 2018).

Kofler R, Nolte V, Schlötterer C. 2016. The impact of library preparation protocols on the consistency of allele frequency estimates in Pool-Seq data. Molecular Ecology Resources 16:118-122. Available from http://doi.wiley.com/10.1111/17550998.12432 (accessed October 25, 2017).

Kujala H, Burgman MA, Moilanen A. 2013, April. Treatment of uncertainty in conservation under climate change.

Laikre L et al. 2009. Neglect of genetic diversity in implementation of the convention on biological diversity. Conservation Biology 24:86-8. Available from http://www.ncbi.nlm.nih.gov/pubmed/20028412 (accessed November 7, 2014).

Laikre L. 2010. Genetic diversity is overlooked in international conservation policy implementation. Conservation Genetics 11:349-354.

Little S, Spencer KL, Schuttelaars HM, Millward GE, Elliott M. 2017. Unbounded boundaries and shifting baselines: Estuaries and coastal seas in a rapidly changing world. Estuarine, Coastal and Shelf Science 198:311-319. Academic Press. 
Available

from

469

470

471

472

473

474

475

476

477

478

479

480

481

482

483

484

485

486

487

488

489

490

https://www.sciencedirect.com/science/article/pii/S0272771417309836

(accessed June 25, 2018).

Lowry DB, Hoban S, Kelley JL, Lotterhos KE, Reed LK, Antolin MF, Storfer A. 2017a. Breaking RAD: an evaluation of the utility of restriction site-associated DNA sequencing for genome scans of adaptation. Molecular ecology resources 17:142152. NIH Public Access. Available from http://www.ncbi.nlm.nih.gov/pubmed/27860289 (accessed July 27, 2017).

Lowry DB, Hoban S, Kelley JL, Lotterhos KE, Reed LK, Antolin MF, Storfer A. 2017b. Responsible RAD: Striving for best practices in population genomic studies of adaptation. Molecular Ecology Resources 17:366-369. NLM (Medline). Available from http://doi.wiley.com/10.1111/1755-0998.12677 (accessed June 6, 2020).

Margules CR, Pressey RL. 2000. Systematic conservation planning. Nature 405:243253. Available from http://www.nature.com/articles/35012251 (accessed January 7, 2019).

Massa SI, Paulino CM, Serrão EA, Duarte CM, Arnaud-Haond S. 2013. Entangled effects of allelic and clonal (genotypic) richness in the resistance and resilience of experimental populations of the seagrass Zostera noltii to diatom invasion. BMC
Ecology
13:39.
Available
from

http://apps.webofknowledge.com/full_record.do?product=WOS\&search_mode=Ma rkedList \&qid=72\&SID=4FIYRxUHo6zj2 $\mathrm{mcAHxr} \&$ page $=1 \&$ doc $=2 \&$ colName $=$ WOS (accessed June 3, 2015).

McMahon K et al. 2014. The movement ecology of seagrasses. Proceedings of the Royal 
499

500

501

502 503 504 505

506

507

508

509

510

Society B: Biological Sciences 281:20140878-20140878. Available from http://rspb.royalsocietypublishing.org/cgi/doi/10.1098/rspb.2014.0878.

McMahon K, Hernawan U, Dawkins K, Van Dijk K-J, Waycott M. 2017. Population genetic diversity, structure and connectivity of two seagrass species, Thalassia hemprichii and Halophila ovalis in the Kimberley. Report of Project 1:46. Available from http://www.wamsi.org.au/sites/wamsi.org.au/files/files/Connectivity_Seagrass Report WAMSI KMRP Project 1_1_3_2_McMahon et al 2017_Final.pdf.

Mead A et al. 2013. Human-mediated drivers of change - impacts on coastal ecosystems and marine biota of South Africa. African Journal of Marine Science 35:403-425. Available from http://www.tandfonline.com/doi/abs/10.2989/1814232X.2013.830147 (accessed November 11, 2014).

Mittell EA, Nakagawa S, Hadfield JD. 2015. Are molecular markers useful predictors of adaptive potential? Ecology Letters 18:772-778.

Nielsen EE, Hemmer-Hansen J, Larsen PF, Bekkevold D. 2009. Population genomics of marine fishes: Identifying adaptive variation in space and time. Molecular Ecology 18:3128-3150.

Nielsen ES, Beger M, Henriques R, Selkoe KA, Der S Von. 2017. Multispecies genetic objectives in spatial conservation planning. Conservation Biology 31:872-882.

Nielsen ES, Henriques R, Toonen RJ, Knapp ISS, Guo B, von der Heyden S. 2018. Complex signatures of genomic variation of two non-model marine species in a homogeneous environment. BMC Genomics 19:1-16. BMC Genomics. 
Paz-Vinas I, Loot G, Hermoso V, Veyssiere C, Poulet N, Grenouillet G, Blanchet S. 2018. the Systematic Conservation Planning for Intraspecific Genetic Diversity. Proceedings of the Royal Society B.

516

Pearse DE. 2016. Saving the spandrels? Adaptive genomic variation in conservation and

Phair NL, Toonen RJ, Knapp I, von der Heyden S. 2019. Shared genomic outliers across two divergent population clusters of a highly threatened seagrass. PeerJ 7:e6806.

Phair NL, Toonen RJ, Knapp ISS, von der Heyden S. 2020. Anthropogenic pressures negatively impact genomic diversity of the vulnerable seagrass Zostera capensis. PeerJ. Journal of Environmental Management 255:109831. Elsevier Ltd. Available from

QGIS Development Team. “QGIS Geographic Information System. Open Source Geospatial Foundation Project." 2012.

Razgour 0, Taggart JB, Manel S, Juste J, Ibáñez C, Rebelo H, Alberdi A, Jones G, Park K.

2018. An integrated framework to identify wildlife populations under threat from climate change. Molecular Ecology Resources 18:18-31.

Reitzel AM, Herrera S, Layden MJ, Martindale MQ, Shank TM. 2013. Going where traditional markers have not gone before: utility of and promise for RAD sequencing in marine invertebrate phylogeography and population genomics.

Rellstab C, Fischer MC, Zoller S, Graf R, Tedder A, Shimizu KK, Widmer A, Holderegger R, 
Gugerli F. 2017. Local adaptation (mostly) remains local: reassessing environmental associations of climate-related candidate SNPs in Arabidopsis.

Rey O, Danchin E, Mirouze M, Loot C, Blanchet S. 2016. Adaptation to Global Change: A Heredity 118: 193-201.

541 Transposable Element-Epigenetics Perspective. Trends in Ecology and Evolution $\begin{array}{llll}\text { 31:514-526. } & \text { Elsevier } & \text { Ltd. } & \text { Available }\end{array}$

Richardson JL, Brady SP, Wang IJ, Spear SF. 2016. Navigating the pitfalls and promise of 543 landscape genetics. Molecular Ecology 25:849-863.

544

545

546

547

548

549

550

551

552 553

Rodriguez-Ezpeleta N, Álvarez P, Irigoien X. 2017. Genetic diversity and connectivity in Maurolicus muelleri in the bay of biscay inferred from thousands of SNP markers. Frontiers in Genetics 8:1-8.

Schwartz MK, Luikart G, Waples RS. 2007. Genetic monitoring as a promising tool for conservation and management. Trends in Ecology and Evolution 22:25-33.

Sgrò CM, Lowe AJ, Hoffmann AA. 2011. Building evolutionary resilience for conserving biodiversity under climate change. Evolutionary Applications 4:326-337.

Simberloff D. 1998. Flagships, umbrellas, and keystones: Is single-species management passe in the landscape era? Biological Conservation 83:247-257.

Skowno AL et al. 2019. National Biodiversity Assessment 2018: The status of South Africa's ecosystems and biodiversity - Synthesis Report. Available from http://opus.sanbi.org/handle /20.500.12143/6362.

Sork VL, Davis FW, Grivet D. 2009. Incorporating Genetic Information Into Conservation 
Planning for California Valley. Proceedings of the 6th symposium on Oak

Woodlands: California's Oaks: today's challenges, tomorrow's opportunities.:497509.

560

561

562

563

564

565

566

567

568

569

570

571

572

573

574

575

576

577

578

579

Timpane-Padgham BL, Beechie T, Klinger T. 2017. A systematic review of ecological attributes that confer resilience to climate change in environmental restoration. PLoS ONE 12:1-23.

Toonen RJ, Puritz JB, Forsman ZH, Whitney JL, Fernandez-Silva I, Andrews KR, Bird CE. 2013. ezRAD: a simplified method for genomic genotyping in non-model organisms.
PeerJ
1:e203.
Available
from

http://www.pubmedcentral.nih.gov/articlerender.fcgi?artid=3840413\&tool=pmce ntrez\&rendertype=abstract (accessed August 1, 2014).

van Niekerk L, Adams JB, Lamberth SJ, MacKay CF, Taljaard S, Turpie JK, Weerts SP, Raimondo DC. 2018. South African National Biodiversity Assessment 2018: Technical Report. Volume 3: Estuarine Realm. Pretoria. Available from http://opus.sanbi.org/bitstream/20.500.12143/791/1/vanNiekerk_et_al_2011.pdf

Van Niekerk L, Turpie J, (eds). 2012. National biodiversity assessment 2011 volume 3 : Estuary component technical report.

von der Heyden S. 2009. Why do we need to integrate population genetics into South African marine protected area planning? African Journal of Marine Science 31:263269. Available from http://www.tandfonline.com/doi/abs/10.2989/AJMS.2009.31.2.14.886 (accessed November 19, 2014). 
von der Heyden S. 2017. Making evolutionary history count: biodiversity planning for

581

coral reef fishes and the conservation of evolutionary processes. Coral Reefs

582

36:183-194. Springer Berlin Heidelberg.

583

von der Heyden S, Beger M, Toonen RJ, Juinio-meñez MA, Ravago-gotanco R, Fauvelot C,

584

585

Bernardi G. 2014. The application of genetics to marine management. Bulletin of Marine Science 90:1-36.

586

587

588

589

590

591

592

593

594

595

596

597

598 
Tables:

Table 1 A description of genomic measures included in this analysis and their relevance to conservation

601 prioritisation (after Beger et al. 2014; Nielsen et al. 2017).

\begin{tabular}{ll}
\hline Genomic measure & Definition \\
\hline Measure: Diversity & \\
\hline Nucleotide diversity (N) & Average number of nucleotide \\
& differences per site between any \\
& two single nucleotide \\
& polymorphisms chosen \\
& randomly from a population
\end{tabular}

Heterozygosity $(\mathrm{H})$

Allelic Richness (AR)

Shared SNPs (S)
The average proportion of loci carrying two different alleles at a single locus within an individual

Average number of alleles per locus

The number of single nucleotide polymorphisms detected per location detected in neutral loci. These SNPs occur in more than one location

Measure: Distinctness

Proportion Private SNPs (PS) Neutral loci that are exclusive to
specific locations

Inferences for conservation

Low $\mathrm{N}$ can indicate small effective population size and therefore low standing variation from which to adapt. Exceedingly low $\mathrm{H}$ indicates an increased risk of inbreeding depression and high extinction risk. High $\mathrm{N}$ indicates the opposite, and therefore potentially increased resilience to environmental change

Low $\mathrm{H}$ is associated with low fitness and decreased capacity to respond immediately following a bottleneck, with the opposite for high $\mathrm{H}$

Low AR is associated with low fitness, resilience and long-term persistence, while the opposite is found for high $\mathrm{AR}$

Low S may indicate low genomic variability and potentially decreased resilience to environmental change, with high $\mathrm{S}$ indicating the opposite

Low PS may indicate high connectivity which could increase metapopulation resilience

High PS indicate highly distinct populations with potentially low connectivity and therefore low resilience to stochastic events. However this could also be driven by local adaptation and therefore increase resilience and evolutionary potential

Measure: Adaptive potential Potential adaptive variation: outlier SNPs - (AV)

Loci that are potentially under selection as they are statistically significantly different from other regions of genome or are strongly correlated with environmental gradients
Low AV could indicate a lack of adaptive potential and therefore low resilience to future environmental changes

High AV may indicate local selection, possibly in response 
Table 2 Conservation prioritisation scenarios and planning objectives.

603

to environmental variables, increasing adaptive potential

602

\begin{tabular}{|c|c|c|}
\hline Conservation features & Abbreviation & Planning objective \\
\hline Baseline (Habitat type + cost) & $\mathrm{B}$ & Habitat \\
\hline Baseline + Nucleotide diversity & $\mathrm{N}$ & \\
\hline Baseline + Heterozygosity & $\mathrm{H}$ & \\
\hline Baseline + Allelic richness & AR & Diversity \\
\hline Baseline + SNPs & $\mathrm{S}$ & \\
\hline Baseline + Private SNPs & $\mathrm{PS}$ & Distinctness \\
\hline $\begin{array}{l}\text { Baseline + Potential adaptive } \\
\text { variation (statistical outliers) }\end{array}$ & AV & Evolutionary potential \\
\hline $\begin{array}{l}\text { Baseline + Allelic richness + } \\
\text { Private SNPs + Outliers }\end{array}$ & ALL & $\begin{array}{l}\text { Habitat, diversity, distinctness and } \\
\text { evolutionary potential }\end{array}$ \\
\hline
\end{tabular}

604

605

606

607

608

609

610

611 


\section{Figures with legends:}

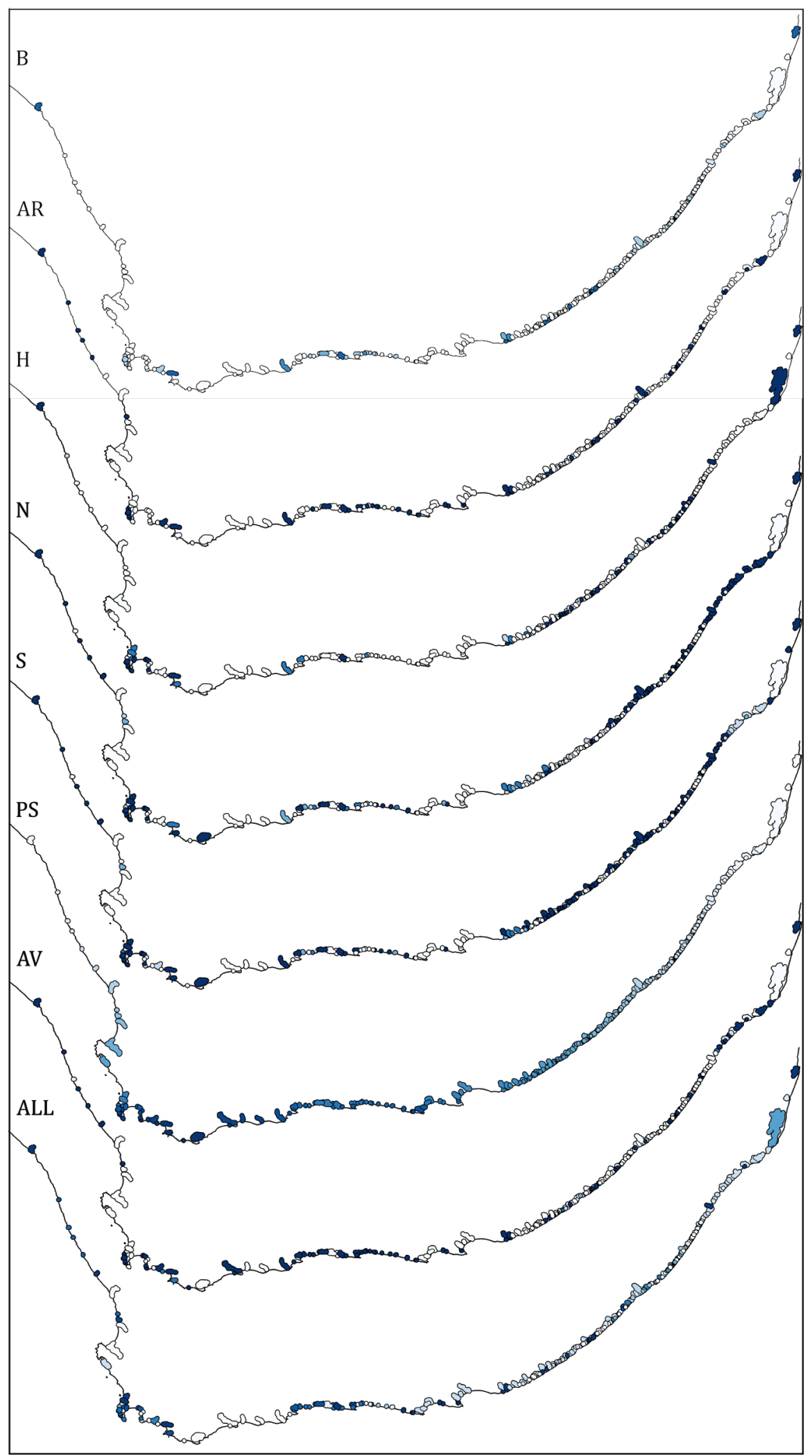

Figure 1 The spatial patterns of selected conservation priority areas across all scenarios with high to low 
heterozygosity, $\mathrm{N}$ = nucleotide diversity, $\mathrm{S}=\mathrm{SNPs}, \mathrm{PS}=$ private SNPs, $\mathrm{AV}$ = potential adaptive variation,

616

ALL=combined (also see Table 2).

617

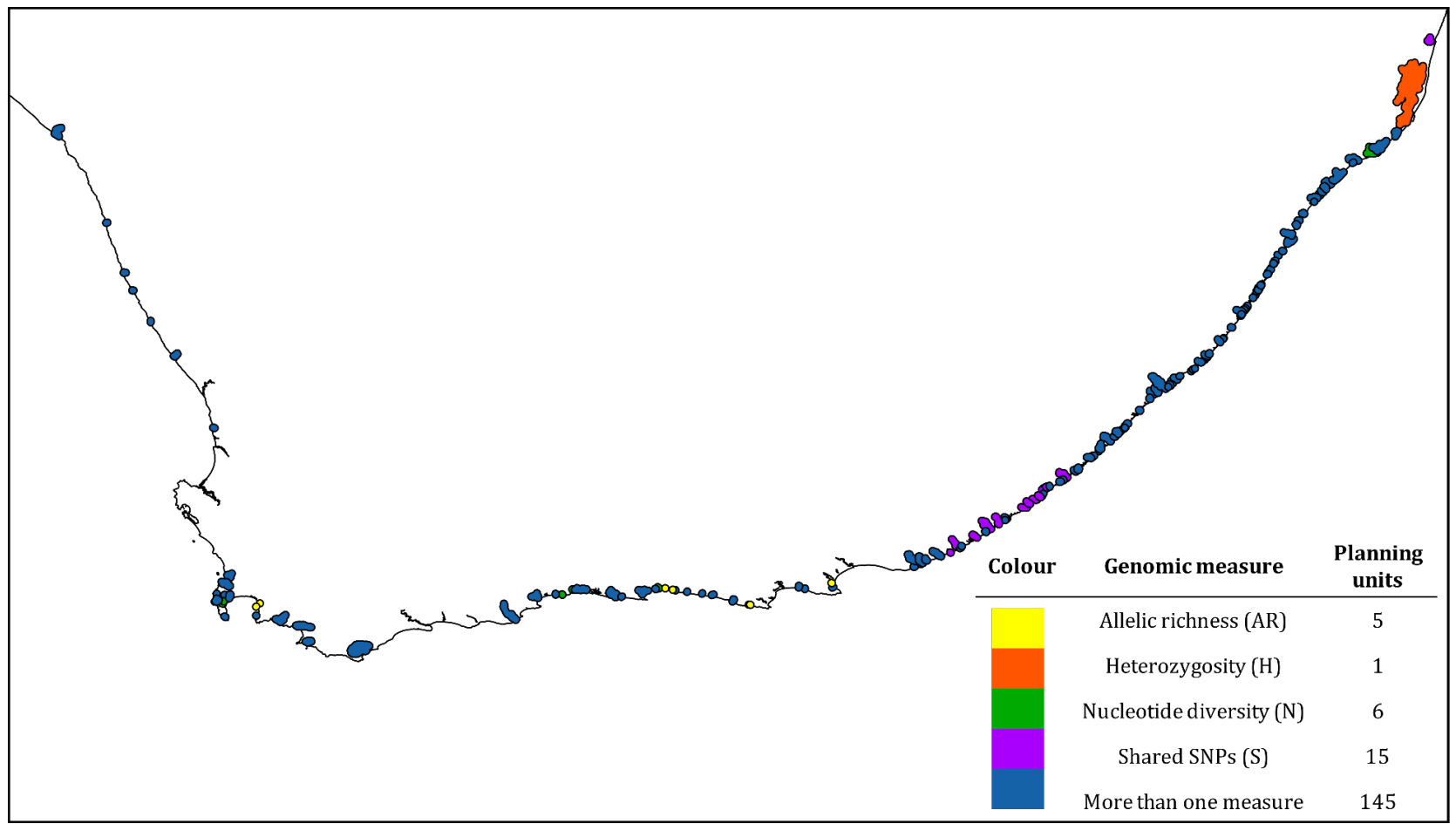

618

619

Figure 2 Spatial patterns of selected priority conservation areas derived from conserving habitat as well as diversity measures, with units selected by more than one scenario in blue and those selected only by the scenario based on AR (allelic richness) in yellow, $\mathrm{H}$ (expected heterozygosity) in orange, $\mathrm{N}$ (nucleotide diversity) in green and S (single nucleotide polymorphisms) in purple. 


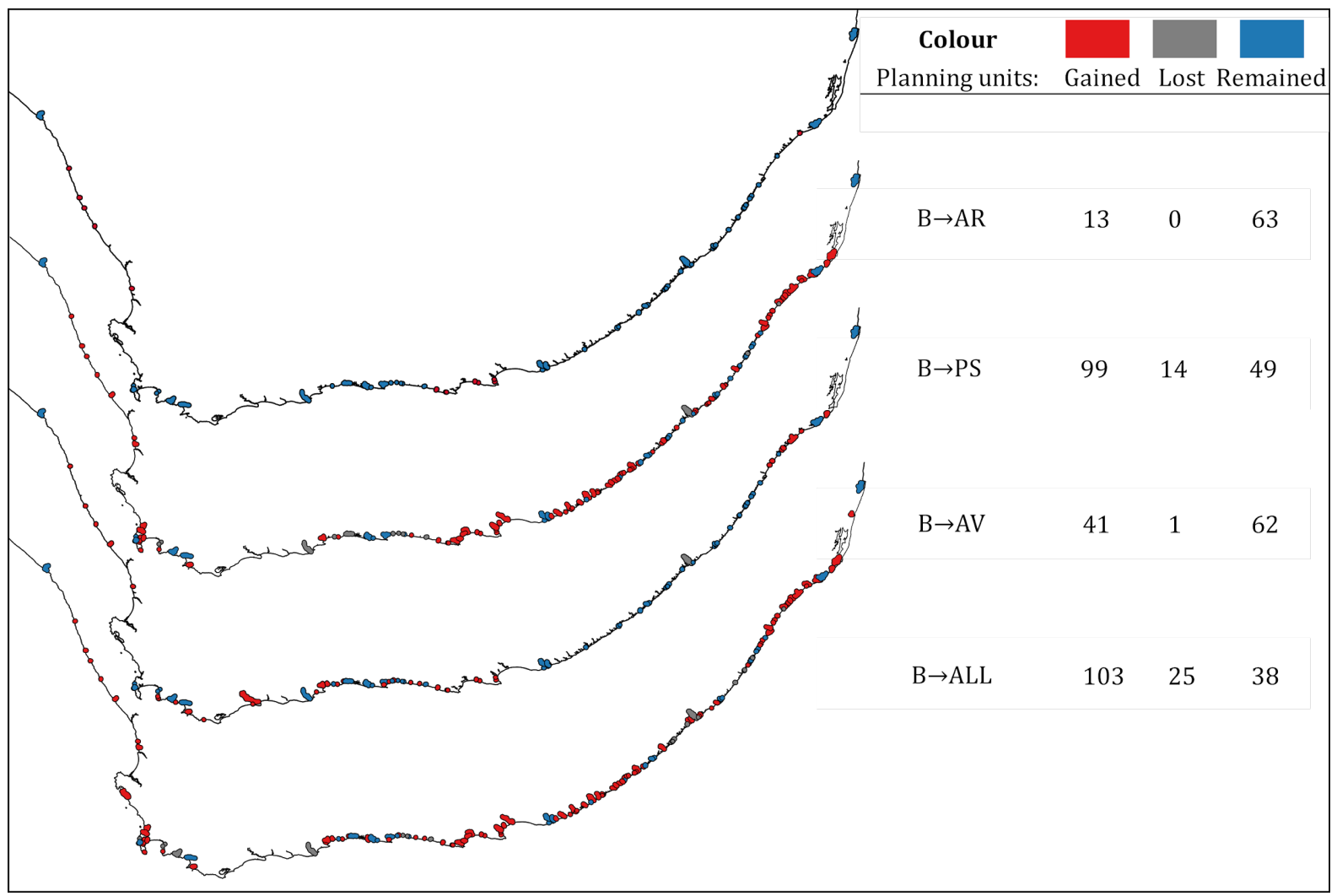

Figure 3 Change in spatial patterns of selected priority conservation areas with the addition of genomic measures of diversity ( $\mathrm{AR}=$ allelic richness), distinctness ( $\mathrm{PS}=$ private single nucleotide polymorphisms), potential adaptive variation ( $\mathrm{AV}$ = adaptive variation), and a combination thereof (ALL) to solely targeting habitat, with units gained in red, lost in grey and remaining selected in blue (number of planning units indicated on the right).

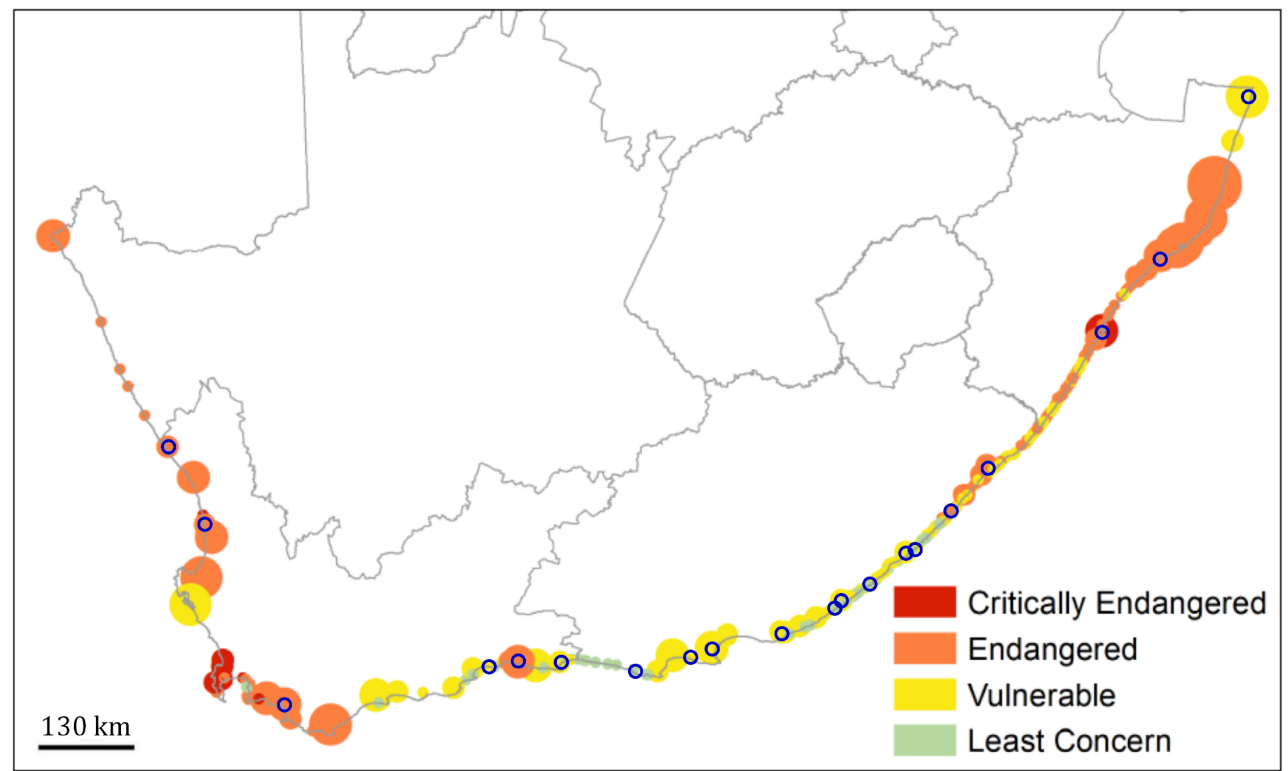

Figure 4 Threat status of South African estuaries (from the NBA; van Niekerk et al. 2018) with the most highly prioritised estuaries under the ALL scenario circled in blue. 